\title{
EFFICIENT DESIGN IN BUILDING CONSTRUCTION WITH RUBBER BEARING IN MEDIUM RISK SEISMICITY: CASE STUDY AND ASSESSMENT
}

\author{
A. B. M. Saiful ISLAM ${ }^{\mathrm{a}}$, Syed Ishtiaq AHMAD ${ }^{\mathrm{b}}$, Mohd Zamin JUMAAT ${ }^{\mathrm{a}}$, \\ Raja Rizwan HUSSAIN ${ }^{c}$, Muhammad Ashiqur RAHMAN ${ }^{\mathrm{a}}$, Kh Mahfuz ud DARAIN ${ }^{\mathrm{a}, \mathrm{d}}$ \\ ${ }^{a}$ Department of Civil Engineering, University of Malaya, Kuala Lumpur, Malaysia \\ ${ }^{b}$ Department of Civil Engineering, Bangladesh University of Engineering and Technology, \\ Dhaka, Bangladesh \\ ${ }^{c}$ CoE-CRT, Department of Civil Engineering, King Saud University, Riyadh, Saudi Arabia \\ ${ }^{d}$ Architecture Discipline, Khulna University, Khulna-9208, Bangladesh
}

Received 09 Feb 2012; accepted 06 Mar 2012

\begin{abstract}
Earthquakes pose tremendous threats to life, property and a country's economy, not least due to their capability of destroying buildings and causing enormous structural damage. The hazard from ground excitations should be properly assessed to mitigate their action on building structures. This study is concerned with medium risk seismic regions. Specifically, the heavily populated capital city Dhaka in Bangladesh has been considered. Recent earthquakes that occurred inside and very close to the city have manifested the city's earthquake sources and vulnerability. Micro-seismicity data supports the existence of at least four earthquake source points in and around Dhaka. The effects of the earthquakes on buildings are studied for this region. Rubber base isolation is selected as an innovative option to lessen seismic loads on buildings. Case studies have been carried out for fixed and isolated based multi-storey buildings. Lead rubber bearing and high damping rubber bearing have been designed and incorporated in building bases. Structural response behaviours have been evaluated through static and dynamic analyses. For the probable severe earthquake, rubber bearing isolation can be a suitable alternative as it mitigates seismic effects, reduces structural responses and provides structural and economic benefits.
\end{abstract}

Keywords: medium risk seismicity, conventional structure, base isolation, multi-storey buildings, structural damage, rubber bearing.

\section{Introduction}

Over the past few decades, a rapid increase of building construction in medium risk seismic prone areas has been observed. Conventional building design approaches pose a huge economic demand in such regions. There is a need to prevent, reduce and remedy any potential seismic threat and damage inflicted on buildings. An alternate approach to incorporating rubber bearings at a building base is a remarkable technology that allows mitigating the seismic hazard in such zones. The earthquake disaster risk index places Dhaka in Bangladesh among 20 most vulnerable cities in the world. The recently measured plate motions at six different sites of Bangladesh clearly demonstrate that Dhaka is moving $30.6 \mathrm{~mm} /$ year in the northeast direction (Khan, Hossain 2005). Furthermore, the rate of strain accumulation is relatively high in and around Dhaka. It may precipitate in an earthquake of magnitude 6.8 in the event of the release of accumulated strain (Khan, Hossain 2005). Building structures experience time varying loads while subjected to such strong earthquake excitations. Earthquakes pose a serious threat to human life and economies as they can damage structures and infrastructure systems.

Designing building structures in Dhaka, Bangladesh to withstand seismic damage is usually based on the traditional design approach. Literature that describes major earthquakes shows the performances of the intended ductile structures to be unsatisfactory. Seismic isolation is one of the most promising alternatives. This type of structural system can be implemented for new structures and as the retrofit of existing building structures. The isolation system is a collection of structural elements which substantially decouples a superstructure from its substructure resting on a shaking ground. The superstructure is supported on base isolators whose dynamic characteristics are chosen to uncouple the ground motion.

For the preceding years, seismic isolation has been increasingly implemented internationally and has proven to be most promising for earthquake safety. The separation of the structure from the harmful motions of the ground occurs by providing flexibility and energy dissipation capability through the insertion of the isolators between the foundation and the building structure (Ismail 
et al. 2010; Kvedaras 2010). Invention of lead rubber bearing (LRB, 1970's) and high damping rubber (HDR, early 1980's) gives a new dimension to the design of base isolated structure. The use of these elastomeric bearings such as HDRB and LRB has shifted to popular applications in recent days (Islam et al. 2011a). Jangid (2007) and Providakis (2008) investigated seismic responses of multi-storey buildings for near fault motion isolated by LRB. Dall'Asta and Ragni (2008) have covered experimental tests, analytical model and nonlinear dynamic behaviour of HDRB.

Although it is a relatively recent technology, seismic isolation for structural application has been thoroughly evaluated and reviewed (Lin et al. 2011; Lu, Lin 2008; Rasiulis, Gurkšnys 2010; Spyrakos et al. 2009; Vaidogas, Šakenaite 2011). Chen et al. (2007) explored the stochastic seismic response analysis and assessed the reliability of base isolated structures. They combined the physical stochastic ground motion model and the probability density evolution method. Base isolator with hardening behaviour under increasing loading has been developed for medium-rise buildings and sites with moderate earthquake risk (Pocanschi, Phocas 2007). Resonant behaviour of base-isolated high-rise buildings under long-period ground motions was dealt with by Ariga et al. (2006) and for long period building responses by Olsen et al. (2008). Wilkinson and Hiley (2006) presented a non-linear response history model for the seismic analysis of high-rise framed buildings. Islam et al. (2011b) presented the optimal isolation systems and the dynamic characteristics of structural responses in multi-storey buildings. The vicinity of Dhaka, Bangladesh was considered in this study. Islam et al. (2011c) added the soft-storey consideration for multi-storey buildings in the same region to evaluate the structural behaviour.

Seismic intensity has been seen to have a significant influence on structural behaviour. Base isolation reduces the lateral forces on the structure and hence the structural excursions (Islam et al. 2012a, 2013) as well as cost (Islam et al. 2010). However in the city of Dhaka in Bangladesh, the concept of isolation of building structures is still young and has rarely been incorporated for multi-storey buildings (Islam et al. 2012b; Jameel et al. 2012a). In addition, there is a lack of proper research on the actual seismic threat in this region and there is an acute need to introduce competent alternatives for building design to confront the seismic threat on structures. Therefore, the objective of this study is to introduce the seismic base isolation through rubber bearing as a reliable alternative in the medium risk seismic prone zone. The seismic status in this medium risk earthquake disaster vicinity has been assessed. Lead Rubber Bearing and High Damping Rubber Bearing have been incorporated in a multi-storey building to provide flexibility and damping to a structure in the event of seismic attack. The implemented isolation systems were seen to be better alternatives to reduce seismic influences and promise significant structural and economic advantages in the study area.

\section{Study area and its seismic status}

Several earthquakes of large magnitude (Richter magnitude 7.0 or higher) with epicentres within Bangladesh and in India close to Indo-Bangladesh have occurred (Ali, Choudhury 1992). Tables 1 and 2 provide lists of the major earthquakes that have affected the surrounding vicinity and the internal region of Bangladesh, respectively (Ali, Choudhury 1994). Data of previous earthquakes inside and around the Bangladesh region are presented in Figure 1 according to magnitude. Furthermore, the country Bangladesh is divided into three zones determined from the earthquake magnitude for various return periods and the acceleration attenuation relationship (Ali, Choudhury 1994) namely zones I, II, III (Fig. 2) being most to least severe gradually (BNBC 1993). This essentially means that Zone I is the least severe and Zone III is the most severe in seismic hazard. It is an alluvial deltaic land with Himalayas on its north and Bay of Bengal on its south. It is located between $20.35^{\circ} \mathrm{N}$ to $26.75^{\circ} \mathrm{N}$ Latitude and $88.03^{\circ} \mathrm{E}$ to $92.75^{\circ} \mathrm{E}$ Longitude. It has an area of about $1,47,570 \mathrm{~km}^{2}$ with population more than 140 million. Most of its area is relatively flat lying in the deltaic plain of the Ganges-Brahmaputra-Meghna river system.

Table 1. Prominent earthquake records affecting Bangladesh (Ali, Choudhury 1994)

\begin{tabular}{|c|c|c|c|}
\hline $\begin{array}{c}\text { Date of } \\
\text { occurrence }\end{array}$ & $\begin{array}{l}\text { Magnitude } \\
\text { in Richter }\end{array}$ & $\begin{array}{c}\text { Name } \\
\text { (Epicenter) }\end{array}$ & $\begin{array}{c}\text { Epicenter } \\
\text { distance from } \\
\text { Dhaka }(\mathrm{km})\end{array}$ \\
\hline 10 Jan 1869 & 7.5 & Cachar Earthquake & 250 \\
\hline 14 Jul 1885 & 7.0 & $\begin{array}{l}\text { Bengal Earthquake } \\
\text { (Bogra) }\end{array}$ & 170 \\
\hline 12 Jun 1897 & 8.7 & $\begin{array}{l}\text { Great Indian } \\
\text { Earthquake }\end{array}$ & 230 \\
\hline 08 Jul 1918 & 7.6 & $\begin{array}{l}\text { Srimangal Earth- } \\
\text { quake (Srimangal) }\end{array}$ & 150 \\
\hline 02 Jul 1930 & 7.1 & Dhubri Earthquake & 250 \\
\hline 15 Jan 1934 & 8.3 & $\begin{array}{l}\text { Bihar-Nepal } \\
\text { Earthquake } \\
\text { (Bihar) }\end{array}$ & 510 \\
\hline 15 Aug 1950 & 8.5 & $\begin{array}{l}\text { Asam Earthquake } \\
\text { (Asam) }\end{array}$ & 780 \\
\hline
\end{tabular}

Table 2. Recent major earthquakes around Dhaka, Bangladesh (Ali, Choudhury 1994)

\begin{tabular}{cclc}
\hline $\begin{array}{c}\text { Date of } \\
\text { occurrence }\end{array}$ & $\begin{array}{c}\text { Magnitude } \\
\text { in Richter }\end{array}$ & $\begin{array}{c}\text { Name } \\
\text { (Epicenter) }\end{array}$ & $\begin{array}{c}\text { Epicenter } \\
\text { distance from } \\
\text { Dhaka (km) }\end{array}$ \\
\hline 08 May 1997 & 6.0 & $\begin{array}{l}\text { Sylhet Earthquake } \\
\text { (Sylhet) }\end{array}$ & 210 \\
21 Nov 1997 & 5.5 & $\begin{array}{l}\text { Chittagong Earth- } \\
\text { quake (Chittagong) } \\
\text { Moheskhali Earth- } \\
\text { quake (Cox's Bazar) }\end{array}$ & 264 \\
22 Jul 1999 & 5.2 & 300 \\
27 Jul 2003 & 5.9 & $\begin{array}{l}\text { Chittagong- } \\
\text { Rangamati Earth- } \\
\text { quake }\end{array}$ & 290 \\
\hline
\end{tabular}

In the generalized tectonic map of Bangladesh, the distribution of epicentres is found to be linear along the Dauki Fault system and random in other regions of Bang- 
ladesh. A close look at the map reveals that the epicentres lie in the weak zones comprising surface or subsurface faults. Most of the events are of moderate rank (magnitude 4-6) and lie at a shallow depth, which suggests that the recent movements occurred in the sediments overlying the basement rocks. In the north-eastern region (Surma basin), major events are controlled by the Dauki Fault system. The events located in and around the Madhupur tract also indicate shallow displacement in the faults separating the block from the alluvium (Khan 2004). Also the tectonic provinces acting around Bangladesh (Ali, Choudhury 1992) show the severity of earthquakes in the region (Table 3 ).

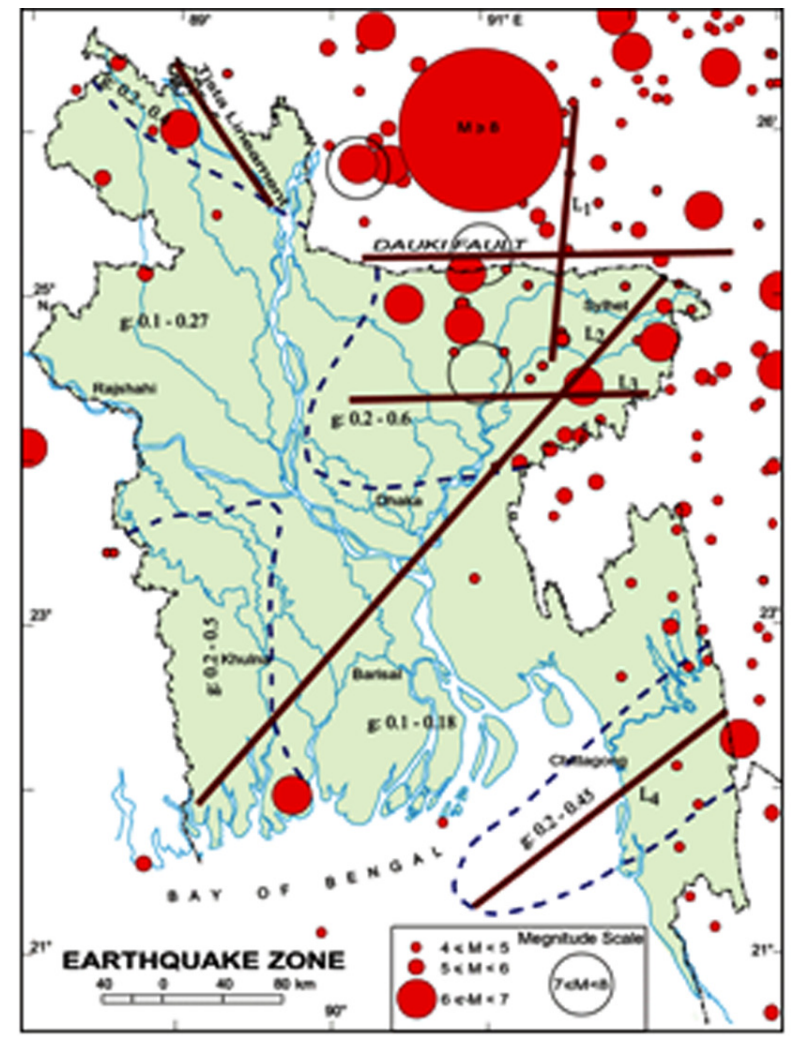

Fig. 1. Earthquake occurrences around Bangladesh as per magnitude (Khan 2004)

Table 3. Tectonic provinces and their earthquake potential (Ali, Choudhury 1992)

\begin{tabular}{lccc}
\hline \multicolumn{1}{c}{ Location } & $\begin{array}{c}\text { Operative } \\
\text { Basis } \\
\text { Magnitude } \\
\text { (Richter) }\end{array}$ & $\begin{array}{c}\text { Maximum } \\
\text { Credible } \\
\text { Magnitude } \\
\text { (Richter) }\end{array}$ & $\begin{array}{c}\text { Depth of } \\
\text { Focus } \\
(\mathrm{km})\end{array}$ \\
\hline Assam fault zone & 8.0 & 8.7 & $0-70$ \\
Tripura fault zone & 7.0 & 8.0 & $0-70$ \\
Sub-Dauki fault zone & 7.3 & 7.5 & $0-70$ \\
Bogra fault zone & 7.0 & 7.5 & $0-70$ \\
\hline
\end{tabular}

Dhaka, located in the central region of Bangladesh, could be affected by any of the four earthquake source zones, presented earlier. Another point of major concern is that there are active faults near the city also. This was realized during the 19 December 2001 magnitude 4+ Dhaka earthquake that caused panic among many city

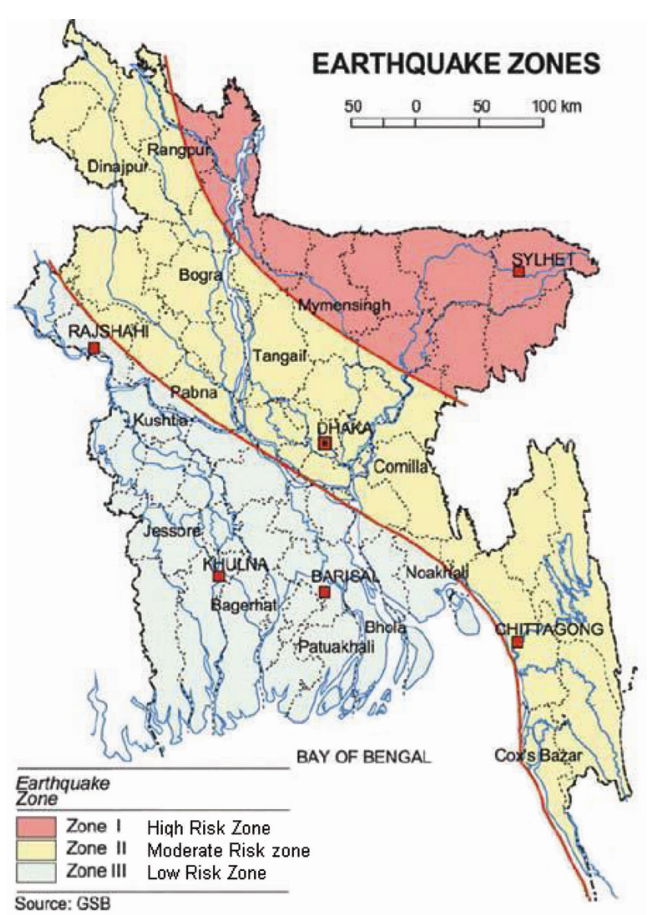

Fig. 2. Seismic zoning map of Bangladesh (Ali, Choudhury 1994)

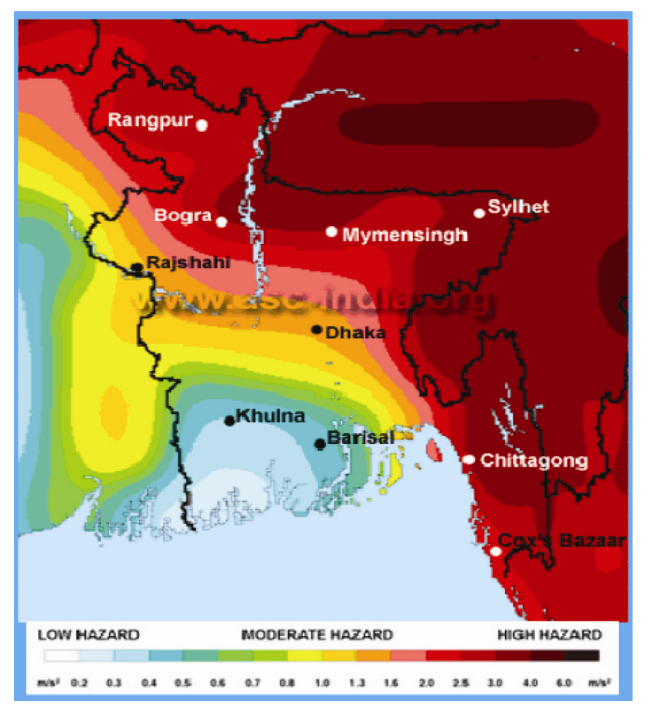

Fig. 3. Earthquake risk in Dhaka, Bangladesh (Ahmed, S., Ahmed, A. 2010)

residents. The epicentre was very close to Dhaka city. Frightened people in several high rise buildings rushed down the stairs, as they felt considerable shaking in the upper floors. The location of a probable earthquake source so near Dhaka with prediction of earthquake magnitude needs to be further investigated (Al-Hussaini 2004). Figure 3 represents the seismic hazard of Dhaka city among the important cities in Bangladesh.

The coincidence of the zones of high particle velocity with the location of faults suggests that the western part of Dhaka city from Mirpur-Kalyanpur to Pagla along Buriganga River and the eastern part of Dhaka city from Uttar Khan-Badda to Demra along Balu River has emerged as a high risk zone. The entire Dhaka megacity 
has been considered from the perspective of an earthquake hazard. It has been divided into four zones of earthquake hazard vulnerability (Fig. 4) ranging between very high risk and low risk (Khan, Hossain 2005).

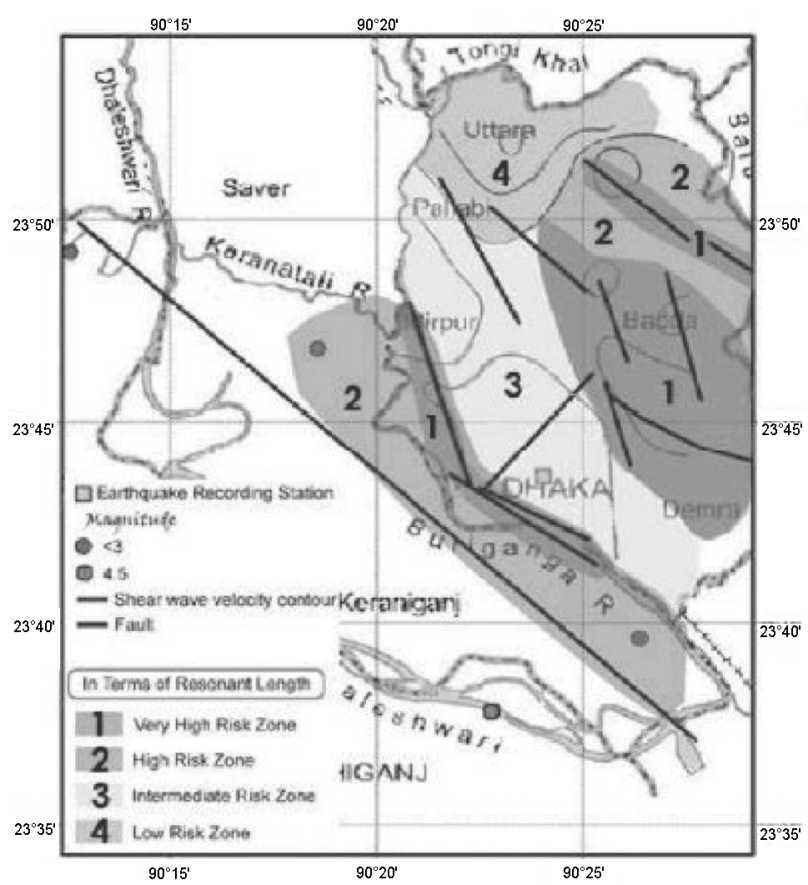

Fig. 4. Earthquake hazard zoning map of Dhaka mega city (Khan, Hossain 2005)

Earthquakes cannot be prevented, but the damage they cause can be greatly reduced with proper structural design, communication strategies, emergency preparedness planning, mass awareness through education and safer building standards. For this reason, the philosophy behind the earthquake resistant design of buildings is to:

- Provide safe and economic design of structures in earthquake hazardous zone;

- Allow only slight, repairable, non-structural damage due to design earthquakes;

- Prevent collapse of structure due to more severe earthquakes.

In order to realize these objectives, a thorough review is needed that extensively covers the past history of earthquake occurrences, number and magnitude of earthquakes occurring each year along with their strength and capability of causing damages and destruction, and major earthquakes throughout the world with a special focus on the Bangladesh scenario.

\section{Earthquake induced damages to buildings}

The enormous amount of energy released by an earthquake causes devastating damages. The energy released by an earthquake of small magnitude 4.3 (Richter) is equivalent to the energy released by the atomic bomb that destroyed Hiroshima, Japan, which is equivalent to about 20 kilotons of TNT. The largest recorded earthquake of magnitude 9.5 (Richter) released as much as $66,000,000$ times that of the Hiroshima atom bombs. The Richter scale ranks earthquakes based on how much the ground shakes $100 \mathrm{~km}$ (60 miles) from the earthquake's epicentre. Table 4 shows earthquakes classified according to their magnitudes.

Table 4. Distinguishing earthquake types by occurring magnitude

\begin{tabular}{cc}
\hline Earthquake Type & Magnitude (Richter) \\
\hline Small & $<5.0$ \\
Moderate & 5.0 \\
Large & 6.0 \\
Major & 7.0 \\
Great & $>=8.0$ \\
\hline
\end{tabular}

Since the Richter scale is a logarithmic scale, an increase of 1 on the Richter scale represents a 10 -fold increase in movement and 32 fold increase in energy release (e.g. an earthquake registering 7 on the scale is 10 times stronger and releases 32 times the energy of an earthquake registering 6 , with the earth's movement being 10 times as distant). As a result, even a slight increase in magnitude corresponds to a high increase in damage. The Moheshkhali earthquake in Bangladesh $(300 \mathrm{~km}$ epicentre distance to Dhaka) of magnitude 5.2 that occurred on July 22, 1999, caused major destruction (Ansary et al. 2001).

Collapsing buildings are the main reason for damage and casualties in an earthquake. To date, a few structural collapses have occurred in and around Dhaka city. During the last 450 years Dhaka was jolted multiple times by local and teleseismic earthquakes of magnitude 4 to 9 on the Richter scale. The intensity of these earthquakes at Dhaka ranged from III to VIII on the Modified Mercalli (MM) intensity scale. Some of these earthquakes, such as those in $1762,1812,1865$, the 1885 Bengal Earthquake and the 1897 Great Indian Earthquake were tremendously damaging to lives and properties in Dhaka City.

In 1812 two earthquakes visited Dhaka - on 10 April and 11 May. The epicentres of these earthquakes are unknown, but might have been close to Dhaka. The earthquakes jolted Dhaka violently and damaged a number of houses and several buildings at Tejgoan (Rizvi 1969). The degree of ground shaking had a MM intensity of VIII. An earthquake that struck in December 2001 with a magnitude of 4.5 and focal depth of $10 \mathrm{~km}$ located very close to Dhaka caused a four-storey building to collapse and injured 100 prisoners in the Dhaka central jail (Ahmed, Ahmed 2010). Figure 5 shows the collapse of building structures due to earthquakes in and around Dhaka.

Earthquake waves induce the ground to move, buildings to shake and cause poorly designed inadequate strength of columns, foundations or weak structures to partially (Fig. 6) or totally (Fig. 7) collapse. Collapse of structures results in human deaths and injuries. Fire hazard (from short circuits and gas explosions) is another post-earthquake threat. In the devastating 1923 Tokyo earthquake, about 130,000 lives were lost due to fire- 
storms fanned by high winds. Zhang et al. (2010) have shown the simultaneous identification of moving masses and structural damage in earthquake excitation.

Therefore, the damage to buildings due to seismic tremors may be classified into three major categories:

1. Damage due to inadequate strength of structural elements (e.g. columns, beams, foundation);

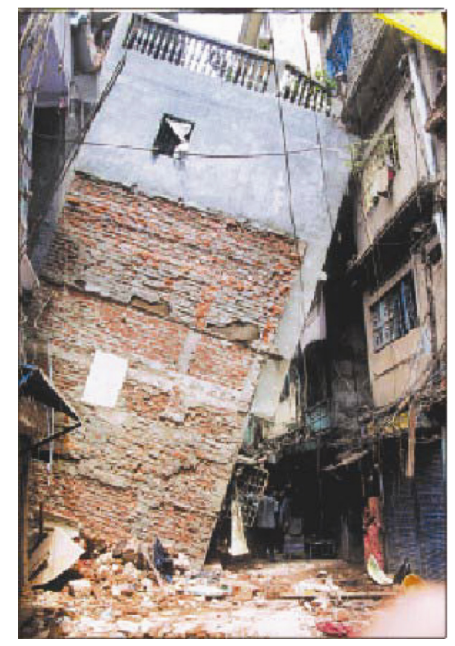

Fig. 5. 6 storey building in old city (Shankhari Bazar) collapsed on June 9, 2004

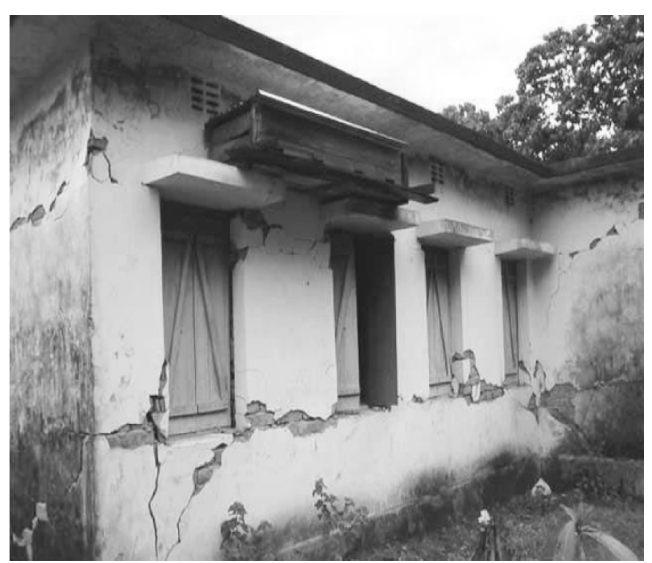

Fig. 6. Partial damage due to earthquake

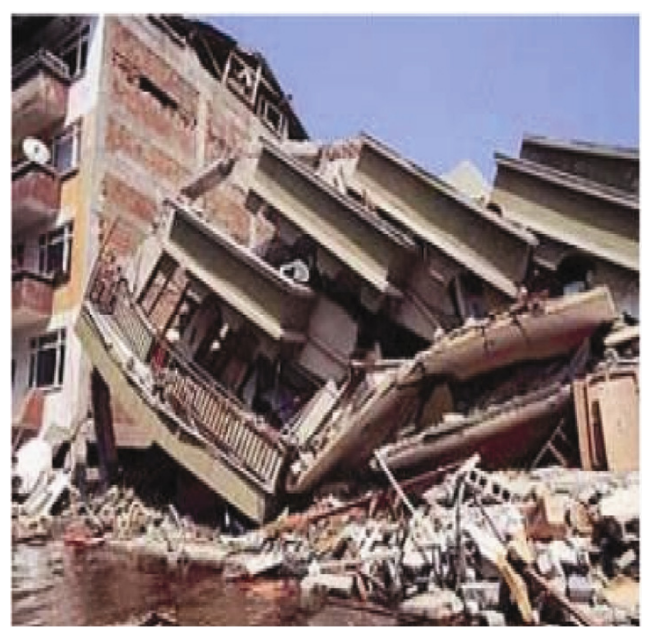

Fig. 7. Total damage due to earthquake
2. Damage due to soil liquefaction;

3. Damage due to post-earthquake threats (e.g. Fire hazards, Tsunamis).

To enhance the structural design of buildings (low rise and high rise buildings) by improving the strength of the columns, beams, etc. in an economic and effective way, an alternative to fixed based structures is to use Base Isolators, depicted in Figure 8.

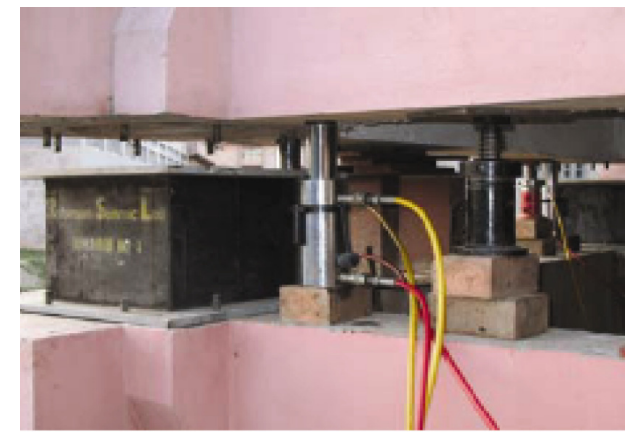

Fig. 8. Separating the superstructure by Base Isolator

\section{Seismic base isolation against conventional design}

Seismic base isolation decouples the building structure from the damaging components of the earthquake input motion, i.e. to prevent the superstructure of the building from absorbing the earthquake energy. The entire superstructure is supported on discrete isolators (Fig. 8) whose dynamic characteristics are chosen to uncouple the ground motion. Some isolators are also designed to add substantial damping. Displacement and yielding are concentrated at the level of the isolation devices, and the superstructure behaves very much like a rigid body. Therefore, the effect of ground motion is minimal. The building can remain serviceable throughout the construction. The base isolator does not involve major intrusion upon the existing super structure.

The isolation technique for structures has been around for some time. The first patent for such a system was filed in 1909 in England. Base isolation methods were implemented during the early 1900's at the Tokyo Imperial Hotel (Kuntz, Tanner 1999). But the entry of base isolation into the mainstream of structural engineering occurred during the 1970's. The isolation technique was used on bridge structures in the early 1970's and on buildings in the late 1970's (Buckle, Mayes 1990). Lead rubber bearing and high damping rubber bearing added the innovative advancement in design of base isolated structures. There are currently hundreds of buildings worldwide that are held up by rubber, i.e. they are not rigidly fixed to the foundations on which they rest. It may come as a surprise that these rubber foundation elements can actually help to minimize earthquake damage to buildings, considering the tremendous forces these buildings must endure in a major quake (Jameel et al. 2012b). Some of the most prominent structures, e.g. Pasadena City Hall, San Francisco City Hall, Salt Lake City, County Building or LA City Hall were mounted on base isolation systems. Here a few famous buildings are shown as an example of isolated structure. The use of isolation in 
Japan continues to increase, especially in the aftermath of the Kobe earthquake. As a result of the superior performance of the West Japan Postal Computer Centre, there has been a rapid increase in the number of permits for base-isolated buildings, including many apartments and condominiums.

Interest in base isolation as an effective means of protecting structures from earthquakes has therefore been revived in recent years. In summary, the following are the five developments that have enabled base isolation to become a practical reality:

1. The design and manufacture of high quality isolation bearings that are used to support the weight of the structure and at the same time release it from earthquake induced forces;

2. The design and manufacture of mechanical energy dissipaters (absorbers) that are used to reduce the movement across the bearings to practical and acceptable levels $100-150 \mathrm{~mm}$ (4-6 inches) and to resist wind loads;

3. The development and acceptance of computer software for the analysis of base-isolated structure which includes nonlinear material properties and the time-varying nature of the earthquake loads;

4. The ability to perform shaking table tests using real recorded earthquake ground motions to evaluate the performance of structures and provide results to validate computer modelling techniques;

5. The development and acceptance procedures for estimating site-specific earthquake ground-motions for different return periods.

Conventional seismic design practice permits the reduction of forces for design below the elastic level on the premise that inelastic action in a suitably designed structure will provide it with significant energy dissipation potential and enable it to survive a severe earthquake without collapse. Inelastic behaviour in specially detailed critical regions, while able to dissipate substantial energy, also often results in significant damage to the structural member, and although the regions may be detailed, their hysteric behaviour will degrade with repeated inelastic cycling. On the contrary, base isolation devices experience large inelastic deformations during a severe earthquake and shift the structural fundamental natural frequency lower and away from the range of frequencies where the earthquake energy is strongest.

Also from the patterns of seismic damage and the types of failure, it is clear that merely increasing the design lateral forces for the design of structural elements (columns, beams, foundations) may not prevent certain types of failures. The more effective technique is to isolate the whole structure from the ground, which prevents most of the horizontal movements from being transmitted to the building during a seismic event. Base isolation has proved to be an effective way of reducing the impact of earthquakes on existing structures under many circumstances. The pattern of seismic effect of a fixed base building is shown in Figure 9a and of an isolated based building in Figure $9 b$.

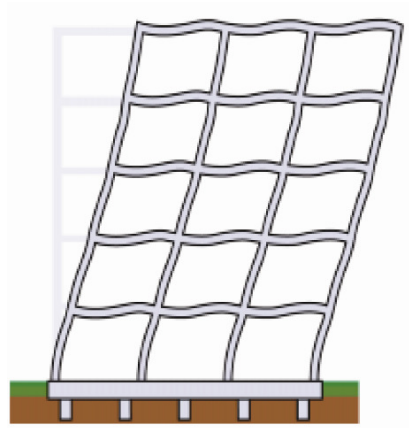

a)

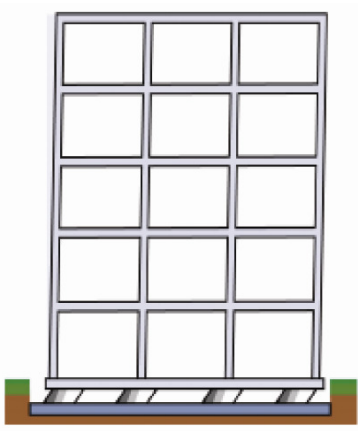

b)
Fig. 9. Differential deflection pattern at: a) conventional fixed based structure; $b$ ) base isolated structure

The installation of isolator considerably increases the time period and damping characteristics of the building. Therefore, it reduces the possibility of resonance of the structure. The installation of isolator thus ensures greater safety of the building by considerably reducing the severity of damage to both the structure and to human lives. This is reaffirmed by a comparative study of performance of various isolation systems on structures (Shrimali, Jangid 2010).

There is a noteworthy diminishment in lateral loads due to the isolation system which allows members to be smaller and still meet the demands. The reduction in member size corresponds to a lessening in steel weight. Therefore, the cost of the building, taking into account only the steel framing, is brought far down. In addition, the isolating strategy contributes to the flexibility of base isolated building to reduce structural needs. The isolation system changes the deflection pattern of the building, thereby reducing the structural responses significantly. For Dhaka region, the seismic base isolation approach has obvious benefits and can be more extensively adopted for building structures.

\section{Case study}

A base-isolated demonstration building has been considered in the region of Dhaka, Bangladesh as part of an ongoing effort to promote the use of base isolation technology for common structures in earthquake-prone developing countries. The superstructure of the demonstration building is a six-storey reinforced concrete frame. Designed isolation system for this project consists of 25 Rubber-steel Bearings. The isolators were connected to the columns and foundation using recessed-type connections at the ground level. Site-specific earthquake time history (Islam et al. 2011d) and response spectra (Islam et al. 2011e) were used for the analysis of the multistorey building with and without isolation.

The 6 storey building is of 4 spacing @ 7.62m c/c in both directions. The selected properties were: $\mathrm{f}^{\prime} \mathrm{c}=28 \mathrm{MPa}$, $\mathrm{fy}=414 \mathrm{MPa}$, dead load (excluding self-weight) $=4.8 \mathrm{KPa}$, live load $=2.4 \mathrm{KPa}$, slab thickness $=150 \mathrm{~mm}$, exterior corner columns are all of $750 \times 750 \mathrm{~mm}$, Exterior middle columns are all $950 \times 950 \mathrm{~mm}$ and all interior columns 
4 span@ $7.62 \mathrm{~m} \mathrm{c/c}$ both ways

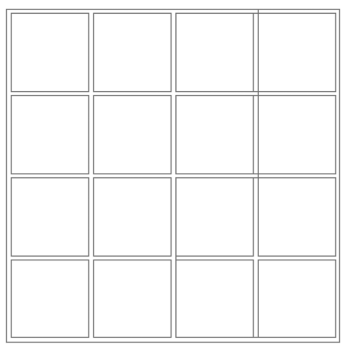

Fig. 10. Plan view of prototype multi-storey building

are $1000 \times 1000 \mathrm{~mm}$ in cross sectional dimensions. The plan view of the demonstration multi-storey building is shown in Figure 10 and 3D modelling view of the building is shown in Figure 11. High damping rubber bearing (HDRB) has been incorporated in the base of interior columns. Furthermore, lead rubber bearings are inserted at exterior column base. The sophisticated finite element program SAP 2000 (2005) was used for analysis and design of structures.

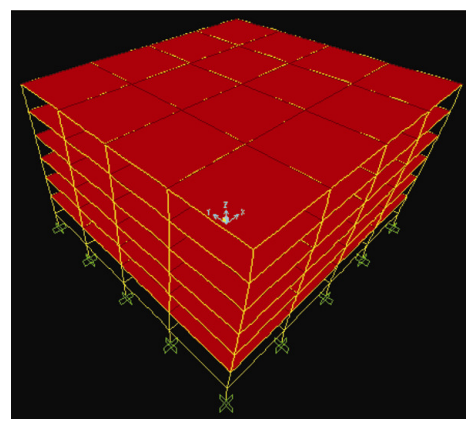

Fig. 11. 3D view of the modelled multi-storey building

Static analysis was carried out following the code BNBC (1993). The results obtained after equivalent static analysis are shown in Table 5 for the conventional fixed based building. From the results, it is seen that the design base shear for earthquake loading is greater than that for wind loading and the structural time period is in within the reasonable value for isolation. Again here, the lateral load due to wind is less than $10 \%$ of the weight of the building, as per the requirement (Kelly 2001; Kelly et al. 2006). Therefore, isolation device is suitable to be incorporated at the base of the structure.

Table 5. Response behaviour in static analysis without isolation

\begin{tabular}{lc}
\hline \multicolumn{1}{c}{ Structural Time Period } & $0.826 \mathrm{sec}$ \\
\hline Design Base Shear (EQ load) & $3265 \mathrm{KN}$ \\
$\begin{array}{l}\text { Design Base Shear (Wind load) } \\
\text { Top story Displacement in UI Direction } \\
\text { (EQ load) }\end{array}$ & $1898 \mathrm{KN}$ \\
$\begin{array}{c}\text { Top story Displacement in U2 Direction } \\
\text { (EQ load) }\end{array}$ & $11.63 \mathrm{~mm}$ \\
$\begin{array}{c}\text { Top story Displacement in UI Direction } \\
\text { (Wind load) }\end{array}$ & $6.6 \mathrm{~mm}$ \\
$\begin{array}{c}\text { Top story Displacement in U2 Direction } \\
\text { (Wind load) }\end{array}$ & $6.1 \mathrm{~mm}$ \\
Building Weight & $39983 \mathrm{KN}$ \\
\hline
\end{tabular}

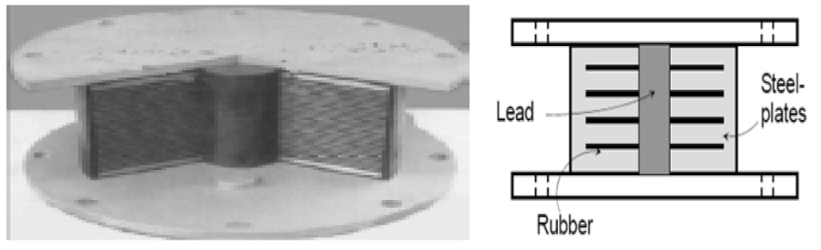

Fig. 12. Geometry and sectional view of lead rubber bearing
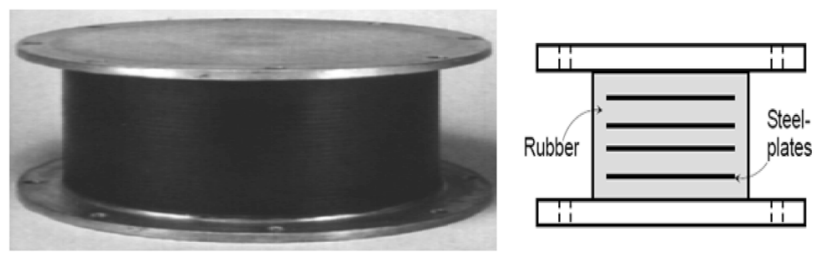

Fig. 13. Geometry and sectional view of high damping rubber bearing

Designs of the base isolators viz. the bearing size, number and thickness of rubber layers, etc. were done for this building using the generated design spread sheet code DESBEA2010. Properties for designing isolator were obtained through the spread sheet. The models of LRB and HDRB were selected as shown in Figures 12 and 13 respectively. The design progression for both rubber bearings follows the flow diagram in Figure 14. It was accomplished following the base isolation design guidelines (Islam et al. 2011f).

Dynamic analyses for time histories (Fig. 15) and response spectrum (Fig. 16) of local suited earthquake have been performed for fixed base structure along with the static analysis. The outputs from these three types of analyses provide insights into the structural behaviour. Design base shear, design base moment and top storey displacement in two orthogonal directions have been illustrated in Table 6. The solution in time history analysis shows the lowest responses. It is obviously desirable as the time history represents the time varying actual behaviour of seismic loading. Whereas response spectrum uses the peak values and the static computation takes approximate over estimations.

The isolation systems have been linked to the bottom of the corresponding column base as per the properties of isolators by the isolation system design procedure. The static analysis is then carried out again for the base isolated structure through modelling in the finite element analysis tool. Both the dynamic approach viz. time history analysis and response spectrum analysis have also been followed for the dynamic evaluation in base isolated case.

Assigning the appropriate values of stiffness to the isolators and analysing the structure with isolator, the results for displacements have been obtained. The structural time period has been observed as $2.62 \mathrm{sec}$. Figure 17 shows the structural displacement pattern of the isolated base building structure in static, response spectrum and time history analysis. The values of displacement follow the descending order as static, response spectrum and time history solution. The seismic performance is evaluated for both the design level and the maximum seismic events. It is noted that for fixed based building, the displacement at 


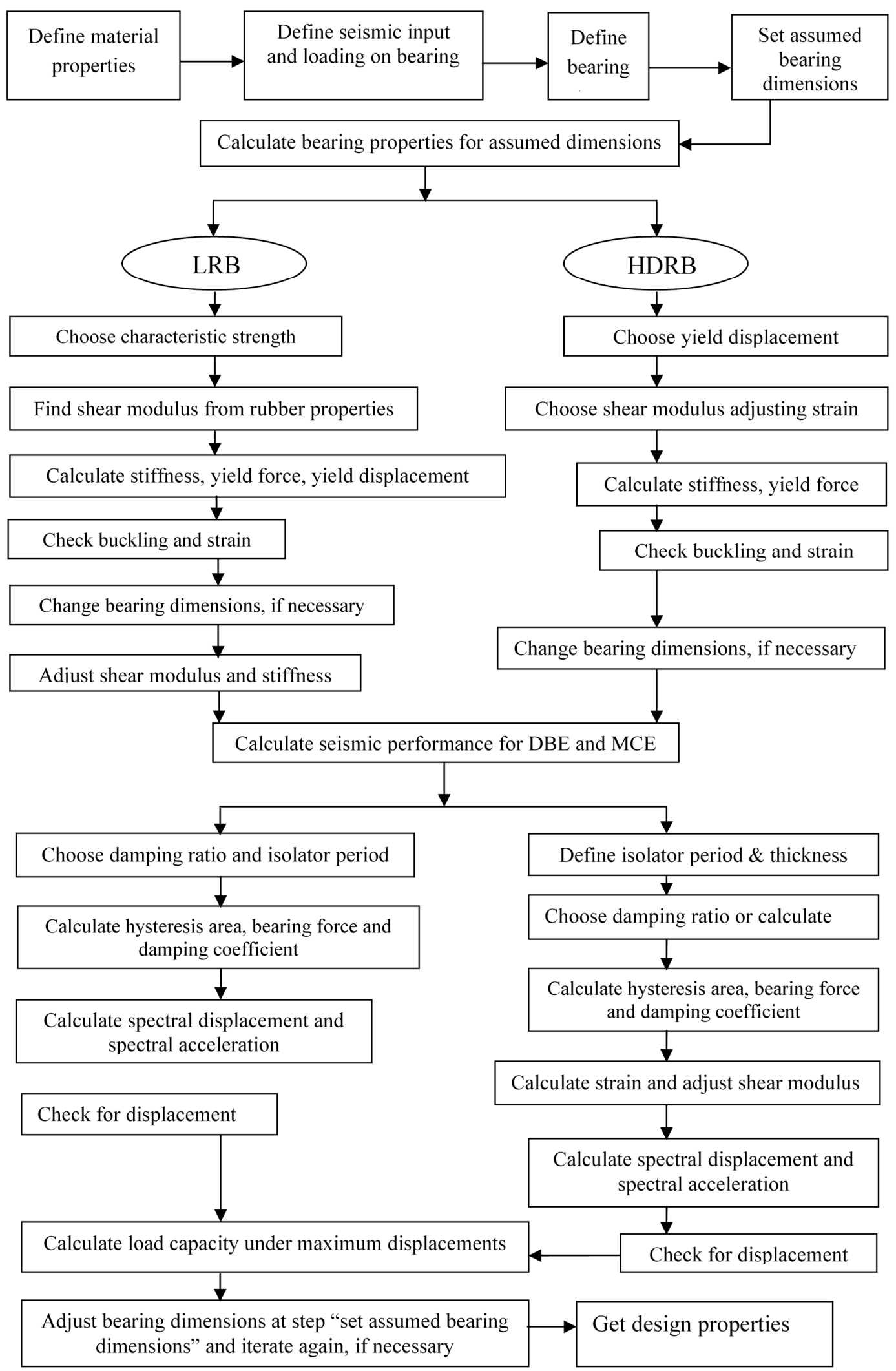

Fig. 14. Flow diagram of isolation system design 
a)

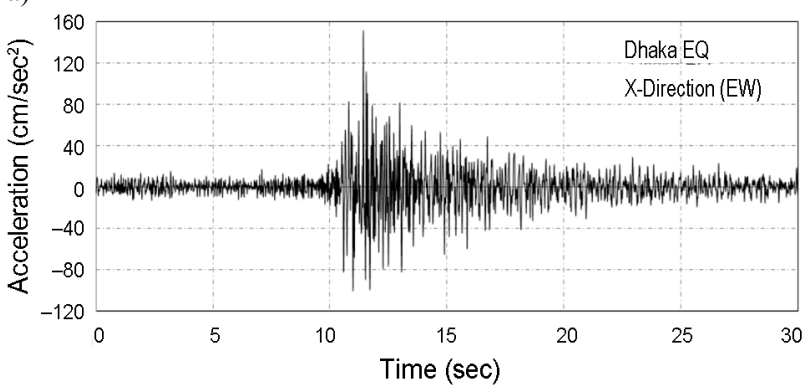

b)

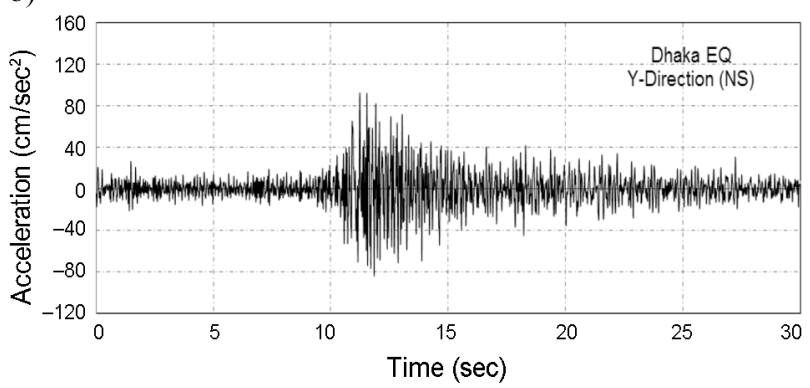

Fig. 15. Time history for Dhaka EQ: a) X-direction; and b) Y-direction

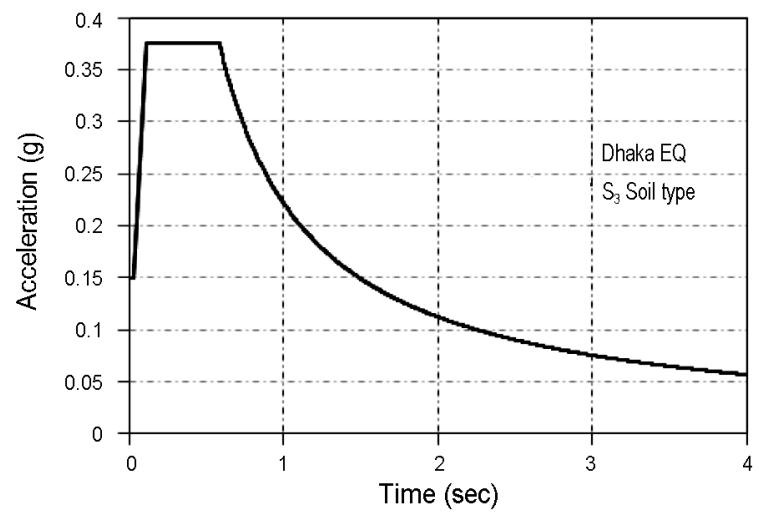

Fig. 16. Acceleration response spectrum for S3 soil for Dhaka

Table 6. Response behaviour in dynamic analysis without isolation

\begin{tabular}{lcc}
\hline & $\begin{array}{c}\text { Response Spectrum } \\
\text { analysis }\end{array}$ & $\begin{array}{c}\text { Time history } \\
\text { analysis }\end{array}$ \\
\hline $\begin{array}{l}\text { Design Base Shear (KN) } \\
\text { in X direction }\end{array}$ & 16221 & 14610 \\
$\begin{array}{l}\text { Design Base Shear (KN) } \\
\text { in Y direction }\end{array}$ & 12666 & 11528 \\
$\begin{array}{l}\text { Design Base Moment } \\
\text { (KN-m) in X direction }\end{array}$ & 93114 & 763726 \\
$\begin{array}{l}\text { Design Base Moment } \\
\text { (KN-m) in Y direction }\end{array}$ & 67047 & 56880 \\
$\begin{array}{l}\text { Top story Displacement } \\
\text { in UI Direction (mm) } \\
\text { Top story Displacement } \\
\text { in U2 Direction (mm) }\end{array}$ & 58.1 & 31.0 \\
\hline
\end{tabular}

base level is zero and shows maximum value at the top storey level. The structure should be more strong and stiff to tackle the responses. Apart from this, in base isolated cases, the isolator itself shows movement. Though the top storey displacement is higher, the total structural drift shows trivial values. This peculiar characteristic of isolation system on structural base makes the superstructure flexible. The design base shear and moment accordingly reduce. Outputs of the design base shear and design base moment in both response spectrum and time history analysis have been illustrated in Table 7. Significant reductions of these values have been observed compared to the fixed based case.

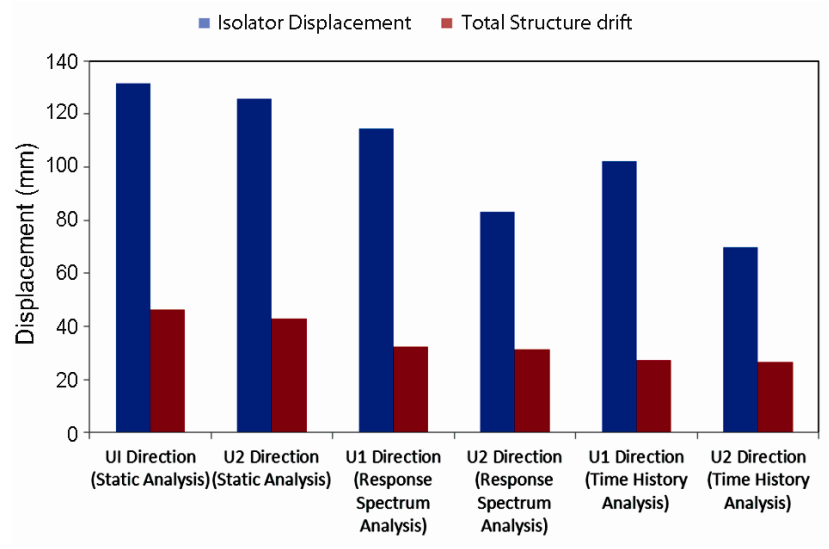

Fig. 17. Displacement for static and dynamic analysis of base isolated structure

Table 7. Design base shear and moment in dynamic analysis of base isolated structure

\begin{tabular}{lcc}
\hline & $\begin{array}{c}\text { Response Spectrum } \\
\text { analysis }\end{array}$ & $\begin{array}{c}\text { Time History } \\
\text { analysis }\end{array}$ \\
\hline $\begin{array}{l}\text { Design Base Shear } \\
\text { (KN) in X direction }\end{array}$ & 7842.5 & 6703.2 \\
$\begin{array}{l}\text { Design Base Shear } \\
(\mathrm{KN}) \text { in Y direction }\end{array}$ & 4926.9 & 3937.3 \\
$\begin{array}{l}\text { Design Base Moment } \\
(\mathrm{KN}-\mathrm{m}) \text { in X direction }\end{array}$ & 38923.7 & 33934.1 \\
$\begin{array}{l}\text { Design Base Moment } \\
(\mathrm{KN}-\mathrm{m}) \text { in Y direction }\end{array}$ & 27955.63 & 24930.6 \\
\hline
\end{tabular}

The results clearly indicate that there is a drastic reduction of structural responses when the isolator bearings are incorporated at the structural base. This reduction serves to improve the structural safety as well as the economic feasibility for the structural design in the study area. Providing flexibility in structural design ensure structural durability and longevity as well along with the protection in ground excitation hazard at medium risk earthquake region. The isolation system can therefore be regarded as efficient alternatives against the traditional approaches of building design.

\section{Conclusions}

There is a great possibility of earthquake occurrence and the inevitable major damages that follow, especially to building structures, at the medium risk seismic zone Dha$\mathrm{ka}$, Bangladesh. A remedy to reduce the extent of damage is presently an urgent need. Base isolation has been introduced as a seismic protection device. Separation of superstructure from the substructure by base isolator reduces the 
seismic dissipated energy. The significant reduction of structural responses allows for greater structural safety and a more economic design, which decisively makes base isolation a better option for seismic design. Though it is a novel idea for Bangladesh, the seismic base isolation system may be adopted in the region especially for areas with extensive urban land use like Dhaka. The proposed system is an effective alternative against conventional fixed based building designs and promises considerable structural and economic benefits.

\section{Acknowledgments}

The authors gratefully acknowledge the support given by University of Malaya (UM) for funding the work through High Impact Research Grant H-16001-00-D000036.

\section{References}

Ahmed, S.; Ahmed, A. H. T. 2010. Disaster risks and risk mitigation in Dhaka/other cities, in International Seminar by Dhaka City Corporation and UNICEF, New Delhi, India.

Al-Hussaini, T. M. 2004. Earthquake risk in Bangladesh: facing the reality, The Daily Star. Dhaka, Bangladesh.

Ali, M. H.; Choudhury, J. R. 1992. Tectonics and earthquake occurrence in Bangladesh, in $36^{\text {th }}$ Annual Convention of the Institute of Engineers, Bangladesh, Dhaka.

Ali, M. H.; Choudhury, J. R. 1994. Seismic zoning of Bangladesh, in International Seminar on Recent Developments in Earthquake Disaster Mitigation. Institution of Engineers Bangladesh in Association with World Seismic Safety Initiative, Bangladesh, Dhaka.

Ansary, M. A.; Al-Hussaini, T. M.; Sharfuddin, M.; Chaudhury, J. R. 2001. 1999 Moheskhali earthquake: a damage study, Journal of Asiatic Society of Bangladesh (Science) 27(2): 139-149.

Ariga, T.; Kanno, Y.; Takewaki, I. 2006. Resonant behaviour of base-isolated high-rise buildings under long-period ground motions, The Structural Design of Tall and Special Buildings 15(3): 325-338. http://dx.doi.org/10.1002/tal.298

BNBC 1993. Bangladesh national building code. Housing and Building Research Institute, Bangladesh Standard and Testing Institute, Bangladesh.

Buckle, I.; Mayes, R. 1990. Seismic isolation: history, application, and performance - a world view, Earthquake Spectra 6(2): 161-201. http://dx.doi.org/10.1193/1.1585564

Chen, J.; Liu, W.; Peng, Y.; Li, J. 2007. Stochastic seismic response and reliability analysis of base-isolated structures, Journal of Earthquake Engineering 11(6): 903-924. http://dx.doi.org/10.1080/13632460701242757

Dall'Asta, A.; Ragni, L. 2008. Nonlinear behavior of dynamic systems with high damping rubber devices, Engineering Structures 30(12): 3610-3618.

http://dx.doi.org/10.1016/j.engstruct.2008.06.003

Islam, A. B. M. S.; Ahmad, S. I.; Jameel, M.; Jumaat, M. Z. 2010. Seismic base isolation for buildings in regions of low to moderate seismicity: a practical alternative design, Practice Periodical on Structural Design and Construction, ASCE 17(1): 13-20. http://dx.doi.org/10.1061/(ASCE)SC.1943-5576.0000093
Islam, A. B. M. S.; Jameel, M.; Jumaat, M. Z. 2011a. Seismic isolation in buildings to be a practical reality: behavior of structure and installation technique, Journal of Engineering and Technology Research 3(4): 99-117.

Islam, A. B. M. S.; Jameel, M.; Jumaat, M. Z. 2011b. Study on optimal isolation system and dynamic structural responses in multi-story buildings, International Journal of the Physical Sciences 6(9): 2219-2228.

Islam, A. B. M. S.; Jameel, M.; Ahmad, S. I.; Jumaat, M. Z. 2011c. Study on corollary of seismic base isolation system on buildings with soft story, International Journal of the Physical Sciences 6(11): 2654-2661.

Islam, A. B. M. S.; Jameel, M.; Rahman, M. A.; Jumaat, M. Z. 2011d. Earthquake time history for Dhaka, Bangladesh as competent seismic record, International Journal of the Physical Sciences 6(16): 3921-3926.

Islam, A. B. M. S.; Jameel, M.; Ahmad, S. I.; Salman, F. A.; Jumaat, M. Z. 2011e. Engendering eartquake response spectra for Dhaka region usable in dynamic analysis of structures, Scientific Research and Essays 6(16): 35193530 .

Islam, A. B. M. S.; Jameel, M.; Uddin, M. A.; Ahmad, S. I. 2011f. Simplified design guidelines for seismic base isolation in multi-storey buildings for Bangladesh National Building Code (BNBC), International Journal of the Physical Sciences 6(23): 5467-5486.

Islam, A. B. M. S.; Hussain, R. R.; Jameel, M.; Jumaat, M. Z. 2012a. Non-linear time domain analysis of base isolated multi-storey building under site specific bi-directional seismic loading, Automation in Construction 22: 554-566.

Islam, A. B. M. S.; Jameel, M.; Uddin, M. A.; Jumaat, M. Z. 2012b. Competent building elevation for incorporating base isolation in aseismic structure, Procedia Engineering 50: 882-892.

Islam, A. B. M. S.; Jumaat, M. Z.; Hussain, R. R.; Alam, M. A. 2013. Incorporation of rubber-steel bearing isolation in multi-storey building, Journal of Civil Engineering and Management 19(Suppl 1), S33-S49.

http://dx.doi.org/10.3846/13923730.2013.801904

Ismail, M.; Rodellar, J.; Ikhouane, F. 2010. An innovative isolation device for aseismic design, Engineering Structures 32(4): 1168-1183.

http://dx.doi.org/10.1016/j.engstruct.2009.12.043

Jameel, M.; Islam, A. B. M. S.; Khaleel, M.; Amirahmad, A. 2012a. Efficient three dimensional modeling of high-rise building structures, Journal of Civil Engineering and Management 19(6): 811-822. http://dx.doi.org/10.3846/13923730.2013.799096

Jameel, M.; Islam, A. B. M. S.; Hussain, R. R.; Khaleel, M.; Zaheer, M. M. 2012b. Optimum structural modelling for tall buildings, The Structural Design of Tall and Special Buildings 22(15): 1173-1185. http://dx.doi.org/10.1016/j.engstruct.2006.12.010

Jangid, R. S. 2007. Optimum lead-rubber isolation bearings for near-fault motions, Engineering Structures 29(10): 25032513. http://dx.doi.org/10.1016/j.engstruct.2006.12.010

Kelly, T. E. 2001. Base isolation of structures: design guidelines. Holmes Consulting Group Ltd.

Kelly, T. E.; Robinson, W. H.; Skinner, R. I. 2006. Seismic isolation for designers and structural engineers. Robinson seismic Ltd.

Khan, A. A. 2004. Earthquake hazard: Dhaka City perspective, The Daily Star. Dhaka, Bangladesh. 
Khan, A. A.; Hossain, M. S. 2005. Recurrence of 1885 Bengal earthquake and hazard vulnerability status of Dhaka metropolitan city, Bangladesh, Oriental geographer 49(2): 205-216.

Kuntz, R. J.; Tanner, D. L. 1999. Earthquake mitigation technology life, safety, structures, contents, and function, Disaster Recovery Journal 5(4).

Kvedaras, A. K. 2010. Stability and ductility of structures: editorial, Journal of Civil Engineering and Management 16(2): 155-158. http://dx.doi.org/10.3846/jcem.2010.15

Lin, L.-K.; Chang, C.-C.; Lin, Y.-C. 2011. Structure development and performance evaluation of construction knowledge management system, Journal of Civil Engineering and Management 17(2): 184-196. http://dx.doi.org/10.3846/13923730.2011.576833

Lu, L.-Y.; Lin, G.-L. 2008. Predictive control of smart isolation system for precision equipment subjected to near-fault earthquakes, Engineering Structures 30(11): 3045-3064. http://dx.doi.org/10.1016/j.engstruct.2008.04.016

Olsen, A.; Aagaard, B.; Heaton, T. 2008. Long-period building response to earthquakes in the San Francisco Bay Area, Bulletin of the Seismological Society of America 98(2): 1047-1065. http://dx.doi.org/10.1785/0120060408

Pocanschi, A.; Phocas, M. C. 2007. Earthquake isolator with progressive nonlinear deformability, Engineering Structures 29(10): 2586-2592.

http://dx.doi.org/10.1016/j.engstruct.2006.12.016

Providakis, C. P. 2008. Effect of LRB isolators and supplemental viscous dampers on seismic isolated buildings under near-fault excitations, Engineering Structures 30(5): 1187-1198.

http://dx.doi.org/10.1016/j.engstruct.2007.07.020
Rasiulis, K.; Gurkšnys, K. 2010. Analyses of the stress intensity of the cylindrical tank wall at the place of the geometrical defect, Journal of Civil Engineering and Management 16(2): 209-215. http://dx.doi.org/10.3846/jcem.2010.23

Rizvi, S. N. H. 1969. Bangladesh District Gazetteers, Dhaka. Government of the People's Republic of Bangladesh, Dhaka, Bangladesh: Bangladesh Government Press.

SAP 2000. 2005. A general purpose linear and non-linear analysis program. Berkeley, California: Computers and Structures Inc.

Shrimali, M. K.; Jangid, R. S. 2010. A comparative study of performance of various isolation systems for liquid storage tanks, International Journal of Structural Stability and Dynamics 10(2): 287-298.

Spyrakos, C. C.; Koutromanos, I. A.; Maniatakis, C. A. 2009. Seismic response of base-isolated buildings including soil-structure interaction, Soil Dynamics and Earthquake Engineering 29(4): 658-668. http://dx.doi.org/10.1016/j.soildyn.2008.07.002

Vaidogas, E. R.; Šakenaitė, J. 2011. A brief look at data on the reliability of sprinklers used in conventional buildings, Journal of Civil Engineering and Management 17(1): $115-125$. http://dx.doi.org/10.3846/13923730.2011.559908

Wilkinson, S. M.; Hiley, R. A. 2006. A non-linear response history model for the seismic analysis of high-rise framed buildings, Computers \& Structures 84(5-6): 318-329. http://dx.doi.org/10.1016/j.compstruc.2005.09.021

Zhang, Q.; Jankowski, Ł.; Duan, Z. 2010. Simultaneous identification of moving masses and structural damage, Structural and Multidisciplinary Optimization 42(6): 907922. http://dx.doi.org/10.1007/s00158-010-0528-4

A. B. M. Saiful ISLAM is a Research Fellow after receiving his $\mathrm{PhD}$ at the Department of Civil Engineering, University of Malaya, Malaysia. He completed his BSc in Civil Engineering and MSc in Structural Engineering from Bangladesh university of Engineering and Technology (BUET), Bangladesh. He is a member of Institution of Engineers, Bangladesh and American Society of Civil Engineers (ASCE). His research interests include offshore structures, nonlinear dynamics, finite element modelling, seismic protection, base isolation, pounding and special tall buildings.

Syed Ishtiaq AHMAD is a Professor of Civil Engineering at Bangladesh University of Engineering and Technology, Dhaka, Bangladesh. His research interests include durability as well as behaviour under cyclic load of buildings particularly made of masonry and brick aggregate concrete.

Mohd Zamin JUMAAT is a Professor and a Head of the Department of Civil Engineering, University of Malaya, Malaysia. He is a member of Institution of Engineers, Malaysia and a member of the Drafting Code Committee for reinforced concrete structures. His research interests include behaviour of offshore structures, reinforced concrete structural elements, concrete materials, self-consolidating concrete, lightweight concrete and green concrete.

Raja Rizwan HUSSAIN is an Associate Professor in CoE-CRT, Department of Civil Engineering, College of Engineering, King Saud University, Riyadh, Saudi Arabia. He received his PhD and MSc in Civil Engineering from the University of Tokyo, Japan for which he was ranked outstanding and was awarded best research thesis award from the University of Tokyo. He received his $\mathrm{PhD}$ in record short period of just two years. He has authored more than 75 publications in less than 5 years of his post $\mathrm{PhD}$ tenure and has received several awards, prizes and distinctions throughout his research and academic career.

Muhammad Ashiqur RAHMAN is a PhD student in the Department of Civil Engineering, University of Malaya, Malaysia. He has completed his BSc in Civil Engineering from Bangladesh university of Engineering and Technology (BUET), Bangladesh and MSc in Structural Engineering from the University of Malaya, Malaysia. He is a member of Institution of Engineers, Bangladesh and student member of American Concrete Institute (ACI). His research interests include reinforced concrete structural members and structural retrofitting.

Kh Mahfuz ud DARAIN is an Associate Professor of Khulna University, Bangladesh. He is pursuing PhD degree in the Department of Civil Engineering, University of Malaya. He received his B.Sc. in Civil Engineering from Rajshahi University of Engineering \& Technology (RUET), Bangladesh and M.Sc. in Structural Engineering from the University of Minho, Portugal. He is a life fellow of Institution of Engineers, Bangladesh and member of American Concrete Institute (ACI). He is dealing research on structural strengthening and structural behaviour of RC member. 